\title{
Stimulus Generalization of Conditioned Eyelid Responses Produced Without Cerebellar Cortex: Implications for Plasticity in the Cerebellar Nuclei
}

\author{
Tatsuya Ohyama, ${ }^{1}$ William L. Nores, and Michael D. Mauk \\ Department of Neurobiology and Anatomy, and Keck Center for the Neurobiology of Learning and Memory, \\ University of Texas Medical School, Houston, Texas 77225, USA
}

\begin{abstract}
In Pavlovian eyelid conditioning and adaptation of the vestibulo-ocular reflex, cerebellar cortex lesions fail to completely abolish previously acquired learning, indicating an additional site of plasticity in the deep cerebellar or vestibular nucleus. Three forms of plasticity are known to occur in the deep cerebellar nuclei: formation of new synapses, plasticity at existing synapses, and changes in intrinsic excitability. Only a cell-wide increase in excitability predicts that learning should generalize broadly from a training stimulus to other stimuli capable of supporting learning, whereas the alternatives predict that learning should be relatively specific to the training stimulus. Here we show that deep nucleus plasticity, as assessed by conditioned eyelid responses produced without input from the cerebellar cortex, is relatively specific to the training conditioned stimulus (CS). We trained rabbits to a tone or light CS with periorbital stimulation as the unconditioned stimulus (US), and pharmacologically disconnected the cerebellar cortex during a posttraining generalization test. The short-latency conditioned responses unmasked by this treatment showed strong decrement along the dimension of auditory frequency and did not generalize across stimulus modalities. These results cannot be explained solely by a cell-wide increase in the excitability of deep nucleus neurons, and imply that an input-specific mechanism in the deep cerebellar nucleus operates as well.
\end{abstract}

Several examples of motor learning including Pavlovian eyelid conditioning and adaptation of the vestibulo-ocular reflex require the cerebellum, and the relevant plasticity appears to occur in the cerebellar cortex and the deep cerebellar or vestibular nuclei (Robinson 1976; Miles and Lisberger 1981; McCormick and Thompson 1984; Perrett et al. 1993; Perrett and Mauk 1995; Peterson et al. 1996; Raymond et al. 1996; Mauk and Donegan 1997; Garcia and Mauk 1998; Garcia et al. 1999; Medina and Mauk 1999, 2000; Medina et al. 2000, 2001; Steinmetz 2000; Ohyama and Mauk 2001; Bao et al. 2002). In eyelid conditioning, evidence for more than one site of plasticity comes from observations that lesions of the cerebellar cortex fail to abolish conditioned eyelid responses (CRs; McCormick and Thompson 1984; Perrett et al. 1993). Pharmacological blockade of the output of the cerebellar cortex to the deep cerebellar nucleus has a similar effect, revealing residual responses with abnormally short, and relatively fixed, latencies (Garcia and Mauk 1998). The results of several recent studies are consistent with the view that these short-latency responses are mediated by plasticity in the deep cerebellar nucleus (Garcia et al. 1999; Medina et al. 2000, 2001; Ohyama and Mauk 2001; Bao et al. 2002).

Evidence at present points to at least three forms of deep cerebellar nucleus plasticity that could mediate the expression of short-latency responses: (1) a cell-wide increase in the intrinsic excitability of deep nucleus cells (Aizenman and Linden 2000); (2) an increase in the strength of mossy fiber-to-deep nucleus (Racine et al. 1986); and/or (3) the formation of new excitatory synapses (Kleim et al. 2002). Results to date provide no clear indications of the relative contributions of these alternatives (but see Perrett and Mauk 1995; Kleim et al. 2002).

Here we provide evidence that a cell-wide change in the

'Corresponding author.

E-MAIL tatsuya.ohyama@uth.tmc.edu; FAX (713) 500-0621.

Article and publication are at http://www.learnmem.org/cgi/doi/10.1101/ Im.67103. excitability of deep nucleus cells alone is insufficient to account for the expression of short-latency responses. If the short-latency responses observed after reversible lesions of the cerebellar cortex (Fig. 1A, black sweep) are mediated solely by a cell-wide increase in the excitability of deep nucleus cells, they should generalize broadly to other stimuli capable of supporting learning (Fig. 1B, left, black), given that many individual deep cerebellar nucleus neurons respond to polymodal inputs after eyelid conditioning training (Tracy et al. 2001; Askenov et al. 2002). In contrast, if a synapse-specific mechanism is involved, then the short-latency responses should show specificity to the training CS (Fig. 1B, right, black). We demonstrate here that short-latency responses exhibit robust stimulus specificity. We also demonstrate that they are not unique to auditory stimuli and do not generalize across different stimulus modalities. These results indicate that at least one input-specific form of plasticity makes a necessary contribution in the cerebellar deep nuclei during eyelid conditioning.

\section{RESULTS}

\section{General Design}

Our main goal was to examine the stimulus specificity of shortlatency responses (see Methods for a definition) that are unmasked after paired CS-US training, when the cerebellar cortex is pharmacologically disconnected by infusing the $\mathrm{GABA}_{\mathrm{A}}$ antagonist picrotoxin into the deep cerebellar nucleus to block inhibitory inputs from Purkinje cells (Garcia and Mauk 1998). To this end, a posttraining stimulus generalization test (see Methods for details of the stimuli used) was conducted after infusing picrotoxin into the anterior interpositus nucleus. In addition, a pretraining generalization test in picrotoxin comprised of the same stimuli was conducted to address whether short-latency responses could be evoked before training. A separate posttraining generalization test was also conducted after infusing the artificial 


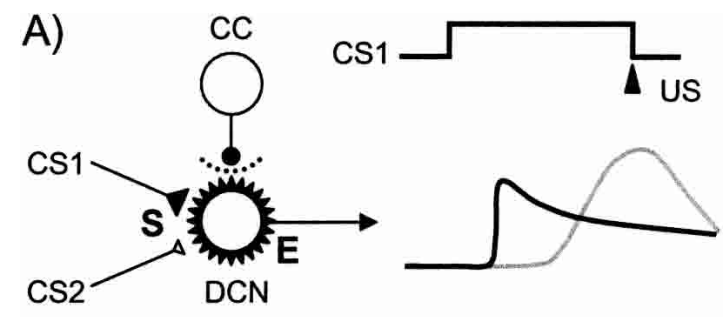

B) EXCITABILITY
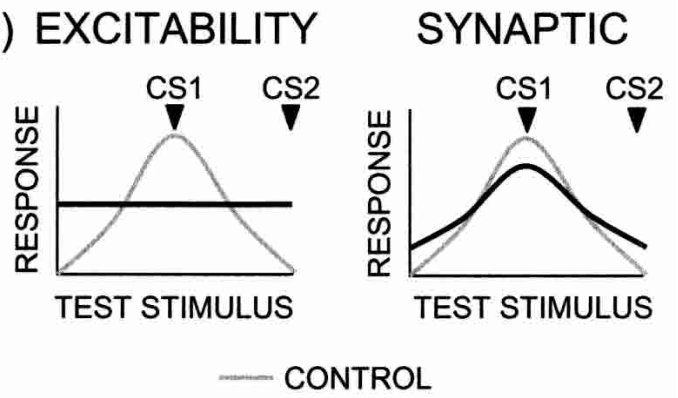

PICROTOXIN

Figure 1 (A) Schematic showing the effect of pharmacologically disconnecting the cerebellar cortex (CC) on conditioned eyelid responses (CRs, gray sweep) established by pairing a previously neutral stimulus (CS1) with the unconditioned stimulus (US). Infusing the GABA $A_{A}$ antagonist picrotoxin into the deep cerebellar nucleus (DCN) produces a reversible lesion of the CC (dotted line), resulting in short-latency responses (black sweep). Two general forms of DCN plasticity that could mediate short-latency responses include synaptic plasticity at the mossy fiberDCN synapse (S) and a cell-wide increase in the intrinsic excitability of DCN neurons (E). (B) Predictions based on alternative hypotheses of DCN plasticity underlying short-latency responses. A cell-wide increase in DCN excitability predicts that short-latency responses should generalize broadly to any stimulus independently capable of supporting learning (left, black). In contrast, a synapse-specific form of plasticity predicts that short-latency responses should be specific to the training CS (right, black). The stimulus specificity of intact CRs is indicated in gray. CS2 refers to a test stimulus never paired with the US, differing from CS1 along a stimulus dimension (auditory frequency, etc.).

cerebrospinal fluid (ACSF) vehicle solution, to test the stimulus specificity of learned responses with the cerebellar cortex intact.

\section{Pretraining Test With Cortex Disconnected}

None of the 12 rabbits exhibited short-latency responses to tones of various frequencies $(1.0 \sim 9.5 \mathrm{kHz})$ or a light presented to the contralateral eye during the pretraining generalization test (Fig. $2 \mathrm{~A})$. This result shows that short-latency responses do not emerge merely as a consequence of tonic removal of the inhibitory output of the cerebellar cortex (Garcia et al. 1999; Bao et al. 2002).

\section{Initial Acquisition of CRs}

Three groups of four rabbits were next trained using a different stimulus as the CS (CS1). Two were trained with a tone as CS1, one with a $1-\mathrm{kHz}$ tone (group 1.0) and a second with a $9.5-\mathrm{kHz}$ tone (group 9.5), to test for stimulus specificity of short-latency responses along the dimension of auditory frequency. A third group was trained with a light directed at the right eye (group L) to test whether short-latency responses were specific to the auditory modality.

Initial learning rates differed across groups. The rate of learning was intermediate for group 1.0, fastest for group 9.5, and slowest for group L. To control for the level of responding to CS1, training was continued for 10 sessions to ensure that learning was asymptotic for each group. All groups reached asymptotic performance by session 5 and maintained similar levels of responding through session 10. A two-way repeated measures (RM) ANOVA on percent CRs during CS-alone trials with group and session, respectively, as the between- and within-subject factors revealed significant main effects of group $\left(F_{(2,9)}=14.17\right.$, $p<0.005)$ and session $\left(F_{(9,81)}=49.42, p<0.001\right)$, as well as a significant group by session interaction $\left(F_{(18,81)}=6.06, p<0.001\right)$. A separate ANOVA restricted to the first five sessions revealed significant main effects of group $\left(F_{(2,9)}=20.91, p<0.001\right)$ and session $\left(F_{(4,36)}=49.15, p<0.001\right)$ as well as a significant group by session interaction $\left(F_{(8,36)}=6.68, p<0.001\right)$, and independent two-way ANOVAs carried out for each pair of groups revealed significant group by session interactions for all pairs: L versus 1.0 $\left(F_{(4,24)}=5.53, p<0.005\right)$, L versus $9.5\left(F_{(4,24)}=9.38, p<0.001\right)$, and 1.0 versus $9.5\left(F_{(4,24)}=4.12, p<0.05\right)$. In contrast, an ANOVA on the last five sessions failed to reveal any significant effect: group $\left(F_{(2,9)}=2.75, p>0.10\right)$, session $\left(F_{(4,36)}<1\right)$, and group by session interaction $\left(F_{(8,36)}<1\right)$. These analyses indicate that although the rate of learning differed across groups, all three groups achieved asymptotic performance prior to testing.

\section{Stimulus Specificity With Cerebellar Cortex Intact}

To assess stimulus specificity of normal CRs, we conducted a posttraining generalization test after an infusion of the ACSF

\section{A) PRE-TRAINING}

B) POST-TRAINING
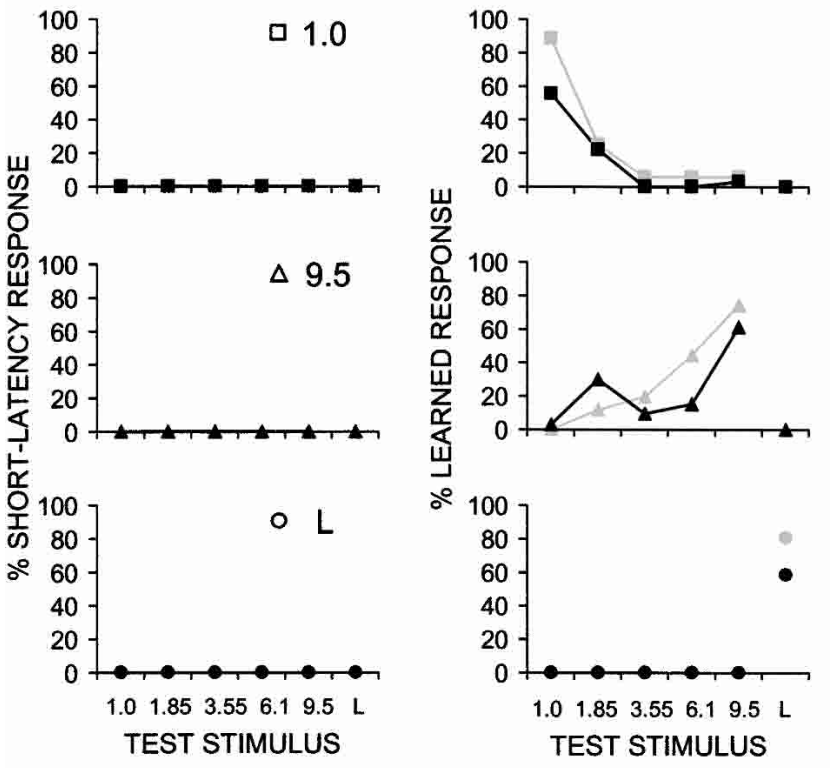

CONTROL (ACSF)

\section{- PICROTOXIN}

Figure 2 (A) Percent trials with a short-latency response (see Methods for definition) to each generalization test stimulus during the pretraining picrotoxin test. (B) Percent trials with a learned response (CRs or shortlatency responses, respectively) during the posttraining tests with the artificial cerebrospinal fluid (ACSF) vehicle (gray) or picrotoxin (black). Short-latency responses were not observed during the pretraining test but were revealed during the posttraining picrotoxin test ( $A$ vs. $B$, black). Both CRs and short-latency responses exhibited stimulus specificity. In this and all subsequent figures, 1.0, 1.85, 3.55, 6.1, 9.5, and $\mathrm{L}$ refer to the generalization test stimuli (pure tones of 1.0, 1.85, 3.55, 6.1, and $9.5 \mathrm{kHz}$ and a monocular light, respectively). The legends in $A$ indicate CS1 (1.0or $9.5-\mathrm{kHz}$ tone or light) for each group. 

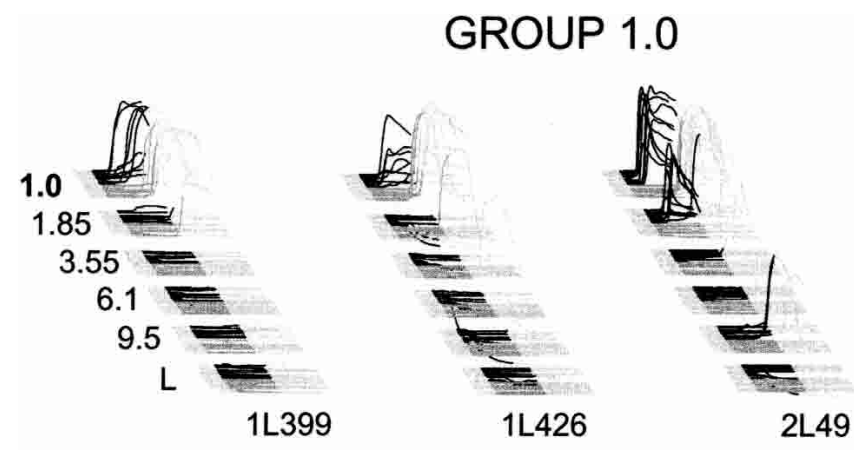

\section{GROUP 9.5}
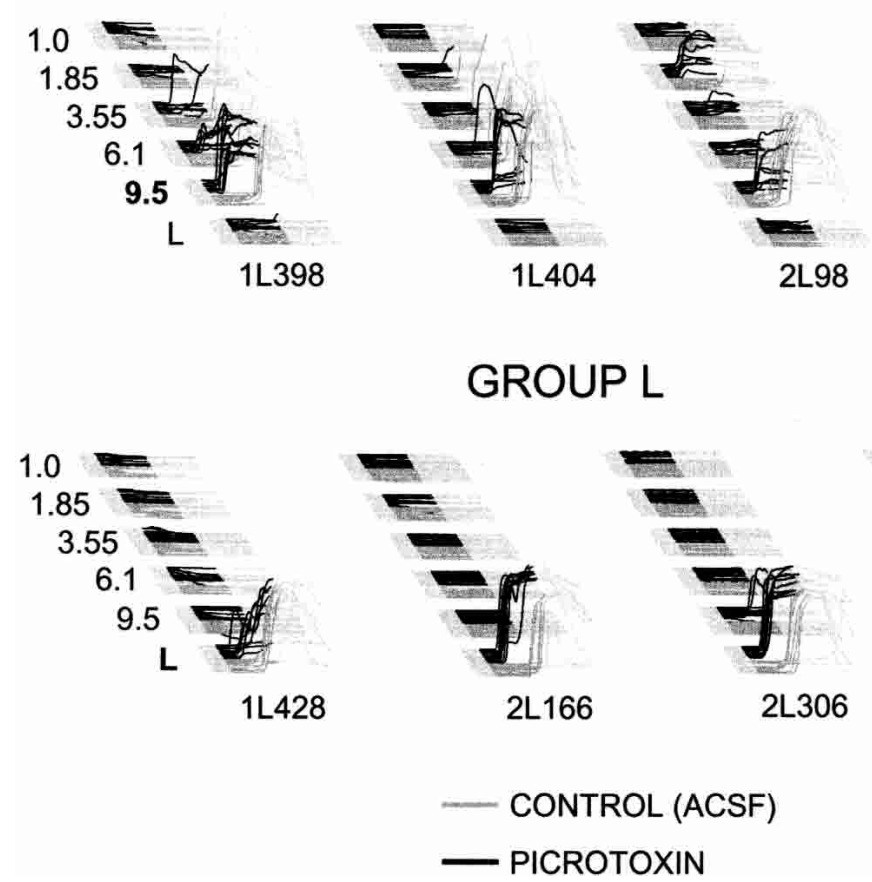

Figure 3 Individual sweeps for each subject grouped by test stimulus during the posttraining ACSF (gray) and picrotoxin (black) tests. Each row shows sweeps from the four subjects of each group. The black and gray lines indicate when the $550-\mathrm{msec}$ test stimulus was present, and each sweep extends to $1000 \mathrm{msec}$ past its onset. Characters in bold on the left indicate CS1.

vehicle solution (Fig. 2B, gray). Except for one response to a 6.1$\mathrm{kHz}$ test tone in one animal from group 9.5, no other shortlatency responses were observed (data not shown). Responding was strongest to CS1 and weak or nonexistent to increasingly different test stimuli, generalizing somewhat within the auditory modality but not across modalities (Siegel et al. 1968; Liu 1971; Solomon and Moore 1975; Powell and Moore 1980; Kehoe and Holt 1984; Kehoe et al. 1984; Holt and Kehoe 1985; Schreurs and Kehoe 1987; Kehoe and Napier 1991; Garcia et al. 2003). For group 1.0, CRs occurred mostly to the $1.0-\mathrm{kHz}$ tone and decreased with increasing frequency of test tones (Fig. 2B, top). For group 9.5, CRs were most frequent to the $9.5-\mathrm{kHz}$ tone and declined as the frequency of test tones decreased (Fig. 2B, middle). Neither group trained to tones responded to the light (Fig. 2B, top and middle), and group L responded exclusively to the light (Fig. 2B, bottom). The gray sweeps in Figures 3 and 4 show individual and averaged responses to each test stimulus.

A two-way RM ANOVA on percent CRs with group (1.0, 9.5, and L) and test stimulus (five tones and the light) as between-
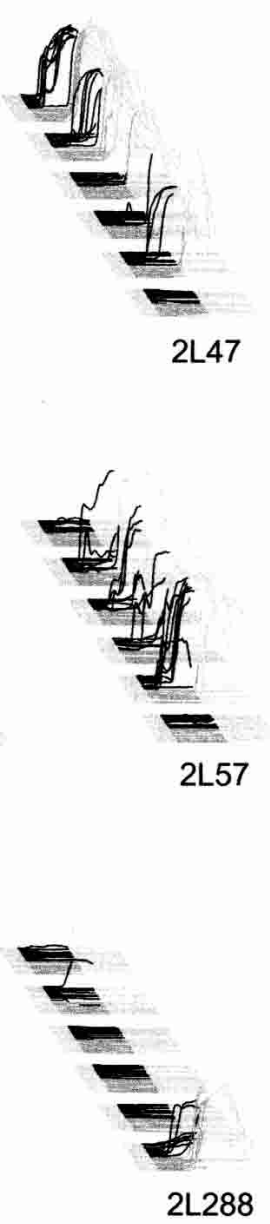

and within-subject factors, respectively, revealed significant effects of test stimulus $\left(F_{(5,45)}=6.01, \quad p<0.001\right)$ and group by test stimulus interaction $\left(F_{(10,45)}=36.82\right.$, $p<0.001)$. There was no effect of group $\left(F_{(2,9)}=1.40\right)$. This indicates that the pattern of generalization depended on CS1, whereas the overall level of CRs did not.

\section{Stimulus Specificity With Cortex Disconnected}

In the key test, we examined generalization of learned responses during pharmacological disconnection of cerebellar cortex. In contrast to the pretraining test (Fig. 2A), all subjects exhibited short-latency responses to CS1 regardless of its modality (Fig 2B, black), showing that their development requires exposure to CS1 and the US. Like CRs in the intact animal, short-latency responses were relatively specific to CS1, generalizing somewhat within the auditory modality (Perrett and Mauk 1995) but not across stimulus modalities. For group 1.0, short-latency responses occurred mostly to the $1.0-\mathrm{kHz}$ tone and declined as the frequency of test tones increased (Fig. 2B, top). For group 9.5, shortlatency responses occurred largely to the 9.5$\mathrm{kHz}$ tone and declined as the frequency of test tones decreased (Fig. 2B, middle). Neither tone-trained group responded to the light (Fig. 2B, top and middle), and group L responded exclusively to the light (Fig. 2B, bottom). The black sweeps in Figures 3 and 4 show individual and averaged responses to each test stimulus.

A two-way RM ANOVA on percent short-latency responses with group and test stimulus as between-subject and withinsubject factors, respectively, revealed significant effects of test stimulus $\left(F_{(5,45)}=3.13\right.$, $p<0.05)$ and group by test stimulus interaction $\left(F_{(10,45)}=11.22, p<0.001\right)$ but no effect of group $\left(F_{(2,9)}=1.72\right)$. These analyses indicate that the pattern of generalization depended strongly on CS1, whereas their overall level of occurrence did not.

\section{Comparison of Stimulus Specificity With and Without Cerebellar Cortex}

The generalization gradients for short-latency responses closely resembled those of normal CRs (Fig. 2B). A comparison of the absolute gradients failed to reveal any difference (Fig. 2B, black versus gray). A three-way RM ANOVA with group as the betweensubject factor and test condition (ACSF or picrotoxin) and test stimulus as within-subject factors revealed significant effects of test stimulus $\left(F_{(5,45)}=7.08, p<0.001\right)$ and group by test stimulus interaction $\left(F_{(10,45)}=38.17, p<0.001\right)$. There was neither an effect of group $\left(F_{(2,9)}=3.72, p>0.05\right)$ nor test condition $\left(F_{(1,45)}=1.97\right)$. None of the other interactions was significant: group by test condition $\left(F_{(2,9)}<1\right)$, test condition by test stimulus $\left(F_{(5,45)}=1.08\right)$, and group by test stimulus by test condition $\left(F_{(10,45)}=2.04, p>0.05\right)$. 


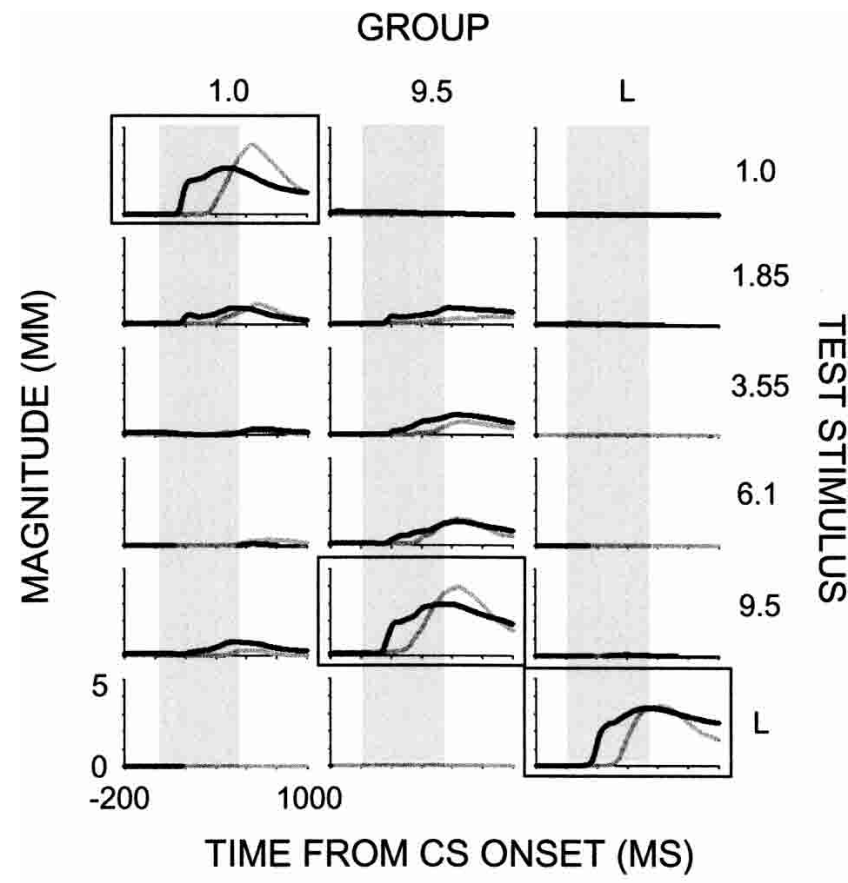

\section{- CONTROL (ACSF) - PICROTOXIN}

Figure 4 Sweeps averaged across separate test stimuli and animals within each group during the posttraining ACSF (gray) and picrotoxin (black) tests. Each sweep begins at $200 \mathrm{msec}$ before and ends $1000 \mathrm{msec}$ past stimulus onset. The shaded area indicates when the test stimulus was present. The sweeps within boxes are responses to CS1.

Because the overall level of responding was generally lower for short-latency responses compared with CRs, for each rabbit we also calculated the percentage of responses to a test stimulus relative to the total number of responses during a picrotoxin or ACSF test, to obtain a more reliable measure of stimulus control (Bitterman 1979). With absolute levels of responding thus controlled, the relative generalization gradients were nearly identical (Fig. 5). To test for independence in the distribution patterns of CRs and short-latency responses, we pooled responses across animals within groups to obtain frequency distributions in each group. A log-linear test (Bishop et al. 1975) with test condition (ACSF or picrotoxin), test stimulus, and group as relevant factors failed to reveal a significant difference in the pattern of distributions (likelihood ratio $\chi_{(11)}{ }^{2}=6.71, p>0.75$ for a model with only group by test stimulus interaction).

\section{Response Magnitudes With and Without Cerebellar Cortex}

A recent study found that in the intact animal, the decline in responding to a test tone differing in frequency from the training tone was due largely to a decrease in the likelihood of full-magnitude CRs (Garcia et al. 2003). To determine whether our data replicated this finding and to compare data in the intact and disconnected conditions, we analyzed the magnitudes of CRs and short-latency responses during the ACSF and picrotoxin tests, respectively. Only responses to test tones in tone-trained animals (groups 1.0 and 9.5) were included because there was no generalization across stimulus modalities (Fig. 2B). With the cerebellar cortex intact, decreased responding was due in part to a decline in the likelihood of CRs. That is, robustly established CRs, if and when they generalized to other stimuli, often did so with full magnitude (Fig. 6, left; Garcia et al. 2003). In contrast, with the cerebellar cortex disconnected, response magnitudes appeared more variable and generally grew smaller as the probe stimulus increasingly differed from CS1 (Fig. 6, right).

Because of the small number of data points per animal, we pooled response magnitudes for all tone trials across animals. The pattern of magnitude distributions depended on whether the cerebellar cortex was intact (ACSF) or disconnected (picrotoxin); intact responses were bimodally distributed, whereas disconnected responses were not (Fig. 7, black versus gray). A log-linear test on magnitude frequencies categorized into four bins $(<0.3$, $0.3-2.3,2.3-4.3$, and $4.3-6.3 \mathrm{~mm}$ ) with test condition (ACSF or picrotoxin), type of test tone (CS1 or non-CS1), and magnitude as relevant factors, revealed that a model including two-way interactions between test condition and magnitude and between magnitude and stimulus type was sufficient to fit the data (likelihood ratio $\left.\chi_{(4)}^{2}=7.48, p>0.11\right)$. This indicates that the differential pattern was similar for responses to CS1 as well as for generalized responses (Fig. 7, top and bottom).

\section{Alternative CS Control}

Finally, to ensure that the lack of cross-modal transfer of shortlatency responses was not caused by an inability of the oppositemodality CS to elicit such responses, we retrained subjects on CS1 for two sessions to re-establish robust responding, and then trained them for 10 sessions with a CS of the opposite stimulus modality (CS2 is the $1.0-\mathrm{kHz}$ tone for group L, the light for groups 1.0 and 9.5). Five rabbits were excluded on the basis of adverse effects because of interpolated testing with glutamate

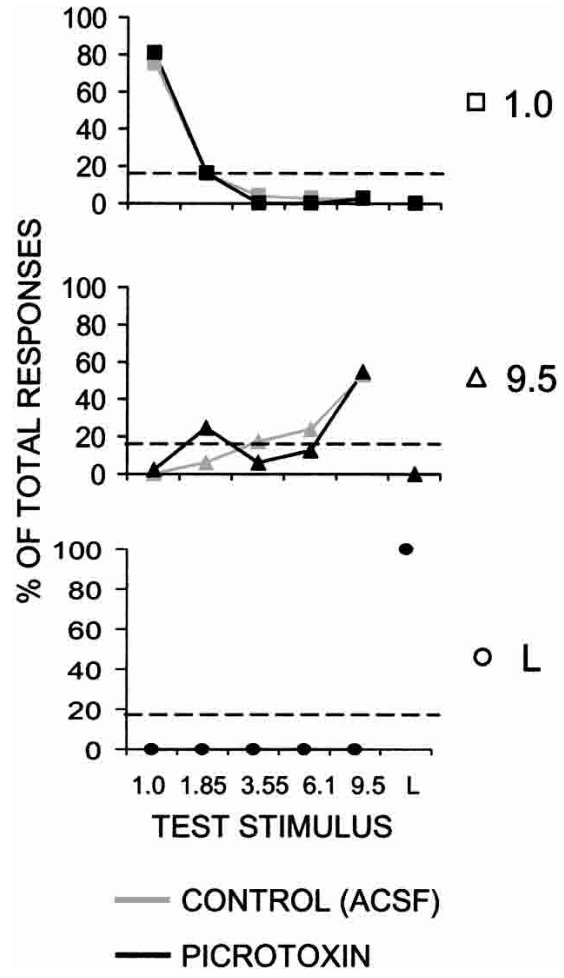

Figure 5 CRs or short-latency responses to test stimuli as a percentage of the total number observed during the posttraining ACSF (gray) or picrotoxin (black) tests, respectively. The stimulus specificity of this relative response measure is nearly identical for CRs and short-latency responses. Dashed lines indicate the relative level of short-latency responses expected from a cell-wide increase in the excitability of deep cerebellar nucleus neurons. 
CONTROL (ACSF)

\section{PICROTOXIN}

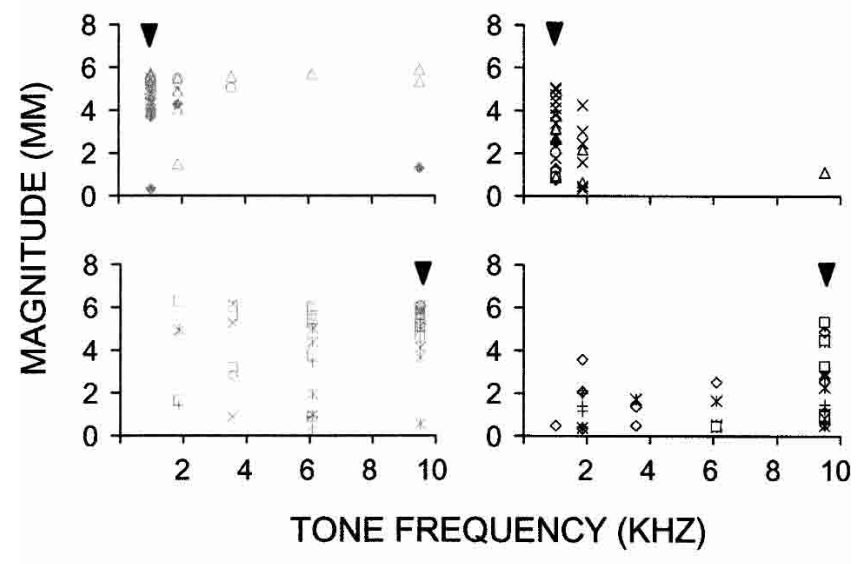

\begin{tabular}{rrrr}
\hline $1 L 399$ & $01 L 426$ & $\times 2 L 49$ & $\Delta 2 L 47$ \\
$* 1 L 398$ & $\square 1 L 404$ & $+2 L 98$ & $\diamond 2 L 57$
\end{tabular}

Figure 6 Scatterplots of response magnitudes to test tones of various frequencies during ACSF or picrotoxin, respectively. (Left) CR and (right) short-latency response magnitudes in the same animals for groups 1.0 (top) and 9.5 (bottom). Arrowheads indicate CS1.

blockers in an unrelated experiment, a decision justified when the ensuing picrotoxin test failed to unmask short-latency responses only for these five subjects. Of the seven remaining subjects (two, two, and three, respectively, in groups 1.0, 9.5, and L), none responded to CS2 during the initial ACSF test (Fig. 2B, gray), but all responded on $>66 \%$ of CS2-alone trials on the tenth day of CS2 training. During the final picrotoxin test, seven and six animals, respectively, showed significantly shorter latencies to onset to CS2 and CS1. (Latency to criterion was a less reliable measure because the magnitudes of the short-latency component of the CR often decreased from the previous picrotoxin test, presumably owing to time-dependent factors.) Independent-sample $t$-tests between pre- and postinfusion CRs to CS2 in each of the seven subjects revealed that latency to onset decreased significantly in one, two, and four subjects at the $0.05,0.005$, and 0.001 levels, respectively. The pooled mean onset latencies for the preand postinfusion CRs were $267(\mathrm{SD}=54)$ and $177(\mathrm{SD}=37) \mathrm{msec}$, respectively, with individual postinfusion means $>200 \mathrm{msec}$ for two animals (213 and $244 \mathrm{msec}$ ) and $<200 \mathrm{msec}$ for the five remaining animals $(168,149,149,175$, and $142 \mathrm{msec})$. Independent sample $t$-tests between pre- and postinfusion CRs to CS1 revealed that latency to onset decreased significantly in one, two, and three subjects at the $0.05,0.005$, and 0.001 levels, respectively. The pooled mean onset latencies for the pre- and postinfusion CRs were $292(\mathrm{SD}=51)$ and $174(\mathrm{SD}=25) \mathrm{msec}$, respectively, with individual postinfusion means $<200 \mathrm{msec}$ in five animals $(143,145$, 176,183 , and $193 \mathrm{msec}$ ) and $204 \mathrm{msec}$ in one animal.

\section{DISCUSSION}

The present findings provide constraints on the nature of the plasticity that mediates the expression of the short-latency responses in eyelid conditioning when the cerebellar cortex is disconnected (Perrett et al. 1993; Perrett and Mauk 1995; Garcia and Mauk 1998; Garcia et al. 1999; Medina et al. 2000, 2001; Ohyama and Mauk 2001; Bao et al. 2002). We have shown that the residual short-latency responses observed after reversible lesions (cf. Garcia and Mauk 1998) are quite specific to the training CS, and that they are not unique to auditory CSs because they can be elicited by a visual CS. Their absence before training and stimulus specificity after training indicates that short-latency responses are learned and associative, consistent with the results of a previous lesion study using electrolytic lesions (Perrett and Mauk 1995) and with the observation that they are not learned with unpaired training (W.L. Nores, J.F. Medina, T. Ohyama, and M.D. Mauk, unpubl.). These data also indicate that, at least under the present conditions, stimulus specificity of deep nucleus plasticity can contribute to that of normal CRs (Figs. 2B and 5). Indeed, the present data do not, for example, exclude the possibility that plasticity in the cerebellar cortex generalizes broadly and that stimulus specificity of deep nucleus plasticity is the limiting factor that produces the observed specificity for normal CRs.

These results have implications for the form(s) of deep nucleus plasticity mediating the short-latency responses induced by eyelid conditioning. In vitro physiological recordings from cerebellar slices in the rat have revealed a nonsynaptic form of plasticity, an increase in the excitability of deep nucleus cells induced upon hyperpolarization followed by rebound depolarization (Aizenman and Linden 2000; see Smith et al. 2002 for excitability changes in vestibular nucleus neurons). It is likely that such a change occurs in eyelid conditioning because learned CS-evoked pauses in Purkinje cell activity (Hesslow and Ivarsson 1994) would lead to precisely the required sequence of events (Medina et al. 2000). However, if a cell-wide increase in excitability were the only form of plasticity mediating short-latency responses, broad generalization should have occurred to other stimuli independently capable of supporting learning (Fig. 1B, left). This prediction follows because many single units in the anterior interpositus nucleus respond to both auditory and visual stimuli after conditioning (Tracy et al. 2001; Askenov et al. 2002). Our data are at odds with this prediction (Figs. 2B and 5). Conceivably, activity-dependent increases in excitability could display a degree of input- or dendrite branch-specificity in vivo (cf. Alkon 1984). Our data do not exclude a mechanism of this sort, although there is at present no evidence for such a hypothesis in deep cerebellar nucleus neurons (but see Schreurs et al. 1997, 1998 for evidence of dendrite-specific excitability changes in Purkinje cells). To summarize, a cell-wide increase in excitability alone is excluded by the present data, and the involvement of a dendrite-specific increase in excitability or synaptic plasticity is required to explain the results. The latter may involve the formation of new synapses (Kleim et al. 2002), synaptic plasticity at pre-existing synapses (Racine et al. 1986; see Grossi and Pettorossi 2001 for mossy fiber-vestibular nucleus plasticity), or both.

The present results also place constraints on models of adaptive CR timing. Many biologically inspired models incorporate only a single site of plasticity in the cerebellar cortex (Moore et al. 1989; Gluck et al. 1990; Fiala et al. 1996; Kistler and DeZeeuw 2002), and thus face the challenge of explaining short-latency responses in the absence of cerebellar cortical input. These models can be salvaged if it is assumed that the short-latency responses are mediated by increases in the excitability of deep nucleus cells (Aizenman and Linden 2000). Yet this modification would still be insufficient to account for the data we report here. The present results leave open the question of whether delay lines (Moore et al. 1989), oscillations (Gluck et al. 1990; Kistler and DeZeeuw 2002), intracellular processes (Fiala et al. 1996), or network dynamics (Medina and Mauk 2000) underlie temporal coding, but do indicate that no model would be complete without an additional plasticity mechanism at the level of the deep cerebellar nucleus that is input specific (Medina and Mauk 2000).

What is the rule for inducing this input-specific plasticity? The present findings are consistent with a computer simulation of the cerebellum that incorporates a climbing fiber-controlled plasticity rule in the cerebellar cortex and a Purkinje cell-controlled rule in the deep cerebellar nucleus (Medina and Mauk 2000; Medina et al. 2000). In the simulation, the granule-cell- 


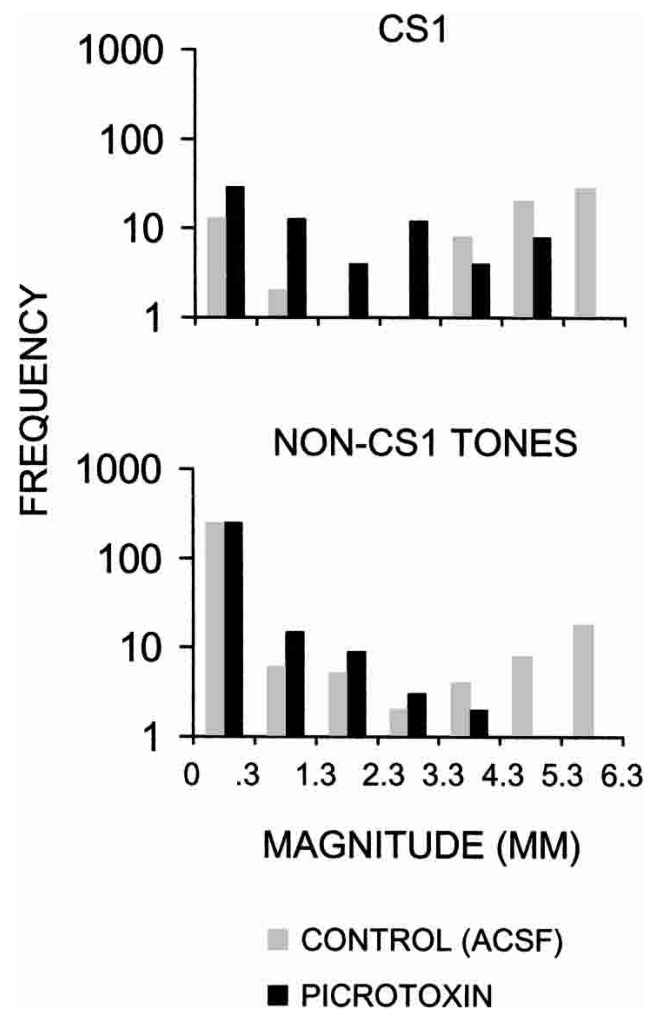

Figure 7 Frequency distributions of response magnitudes pooled across tone-trained animals as a function of stimulus type (CS1 or nonCS1 test tones) and test condition (ACSF or picrotoxin). Responses in the intact condition are bimodal (gray), in contrast to responses with the cerebellar cortex disconnected (black). This difference is observed for responses to CS1 (top) as well as for generalized responses (bottom).

Purkinje-cell synapses undergo long-term depression (LTD) or potentiation (LTP) depending on whether or not climbing fiber activity coincides with presynaptic activity, consistent with plasticity rules that have been well-characterized physiologically (Hansel et al. 2001; Hartell 2002). Although much less is known of the synaptic physiology of mossy fiber-deep nucleus synapses (Racine et al. 1986), for reasons to be explained below, they are hypothesized to undergo LTP or LTD depending on whether a decrease or increase in Purkinje cell activity coincides with mossy fiber activity (Medina and Mauk 1999, 2000; Medina et al. 2000).

In principle, any of three possible postsynaptic signals could, in conjunction with activity in a presynaptic mossy fiber, induce plasticity at the mossy fiber-deep nucleus synapse: the activity of (1) the climbing fiber sending collaterals to the deep nucleus; (2) the deep cerebellar nucleus itself; or (3) the Purkinje cells projecting to the deep nucleus (Medina and Mauk 1999). However, several lines of evidence favor the control of plasticity induction by Purkinje cells, as first proposed by Miles and Lisberger (1981) for adaptation of the vestibulo-ocular reflex. Indirect evidence comes from recent computer simulations. Medina and Mauk (1999) used simulations without temporal coding to test the three induction rules and found that the climbing fiber and deep cerebellar nucleus (i.e., Hebbian) rules led to synaptic drift, whereas the Purkinje cell rule did not. In addition, only the latter significantly delayed degradation of motor memories in the presence of background activity (Medina and Mauk 1999).

Recent empirical evidence also supports the Purkinje cell rule. First, cerebellar cortex lesions prevent acquisition (Garcia et al. 1999; Bao et al. 2002), a result inconsistent with a climbing fiber rule that predicts learning should proceed independently in the cerebellar cortex and deep cerebellar nucleus. Learning to a second CS was prevented completely when the presence of shortlatency responses was used as a criterion for determining the effectiveness of anterior lobe lesions after initial training to another CS (Garcia et al. 1999). A recent study also found that when picrotoxin was infused into the deep cerebellar nucleus to block the output of the cerebellar cortex, rabbits could not acquire CRs (Bao et al. 2002). Second, short-latency responses unmasked after physical or reversible lesions of the cerebellar cortex have been shown to be highly resistant to extinction compared with normal CRs (Perrett and Mauk 1995; Medina et al. 2001), implying that reversal of plasticity in the deep nucleus also requires the cerebellar cortex. If the presence or absence of climbing fiber activity determined whether the mossy fiber-deep nucleus synapses would undergo LTP or LTD, it is hard to see why extinction of short-latency responses would fail outright (Perrett and Mauk 1995) or proceed so slowly (Medina et al. 2001). Collectively, the effects of cerebellar cortex lesions on acquisition and extinction rule out the climbing fiber rule, and imply that the plasticity rules in the cerebellar cortex and deep nucleus are not independent and that the latter depends on the former. This conclusion is also consistent with requirements for inducing increases in the excitability of deep nucleus cells (Aizenman and Linden 2000) and adaptation of the vestibulo-ocular reflex (Miles and Lisberger 1981).

Finally, the results of the pretraining test in the present study (Fig. 2A) are potentially inconsistent with a deep cerebellar nucleus rule, which predicts that releasing the deep cerebellar nucleus cells from the inhibitory output of Purkinje cells alone would increase their firing and strengthen the mossy fibernucleus synapses active during a CS. The rule thus predicts that short-latency responses should be acquired to any stimulus presented during removal of cerebellar cortical output. However, no short-latency responses were observed to any of the tones or light (Fig. 2A). This indicates that removal of tonic inhibition alone is not a sufficient condition for inducing synaptic plasticity in the deep nucleus (Garcia et al. 1999; Bao et al. 2002). Together with the evidence for cerebellar cortex lesions, a transient pattern of deep nucleus inhibition followed by disinhibition in response to a CS, a condition that requires Purkinje cell input and develops only with paired training (Hesslow and Ivarsson 1994; Bao et al. 2002), appears necessary for the induction of deep nucleus plasticity (Aizenman and Linden 2000; Medina et al. 2001).

What is the role of a cell-wide increase in the excitability of deep cerebellar nucleus neurons? One possibility is that it contributes to savings or "learning to learn" (Kehoe 1988; Kehoe et al. 1995) during rapid reacquisition after extinction (Napier et al. 1992; Medina et al. 2001) or cross-modal acquisition (Kehoe et al. 1984, 1995; Macrae and Kehoe 1999), in which learning to an old CS after extinction or to a new CS after training with a different modality CS, respectively, is faster compared with untrained controls. For example, a cell-wide increase in deep nucleus excitability alone might mediate cross-modal savings (Hansel et al. 2001), whereas both increased excitability and input-specific plasticity might underlie savings in relearning after extinction (cf. Medina et al. 2001). If both input-specific plasticity and a cell-wide increase in excitability in the deep nucleus are necessary for the expression of short-latency responses (i.e., the presence or absence of increased excitability determines whether or not the input-specific plasticity is expressed), and expression of normal CRs requires plasticity in the cerebellar cortex in addition to both forms of deep nucleus plasticity, the combined set of hypotheses could also explain why (1) stimulus specificity of short-latency responses is so robust despite the overlap of tone and light inputs in the deep nucleus (Figs. 2B and 5); (2) there is no immediate cross-modal generalization of short-latency responses or normal 
CRs (Figs. 2B and 5; Kehoe and Holt 1984; Kehoe et al. 1984; Holt and Kehoe 1985; Schreurs and Kehoe 1987; Kehoe and Napier 1991); and (3) savings are generally more robust in relearning after extinction than in cross-modal acquisition (Macrae and Kehoe 1999). Although our study was not designed to address such issues directly, future experiments could investigate the different contributions of the cell-wide and input-specific changes in the deep cerebellar nuclei in different forms of savings.

In summary, our results indicate that the deep nucleus plasticity involved in cerebellar learning includes not only cell-wide changes in the intrinsic excitability of deep nucleus neurons, but an additional plasticity mechanism at the level of the deep cerebellar nucleus that is input specific. The present findings constitute a significant set of data (see also Perrett and Mauk 1995) that are reproducible with a computer simulation of the cerebellum (Medina and Mauk 2000; Medina et al. 2001) only if it incorporates an input-specific form of deep nucleus plasticity. The results are also consistent with a deep nucleus plasticity rule controlled by the activity of Purkinje cells (Medina and Mauk 1999). Future studies may reveal the relative contributions of excitability changes, synapse formation, and mossy-fiber-to-nucleus LTP/ LTD in cerebellar learning.

\section{MATERIALS AND METHODS}

\section{Subjects and Surgery}

Twelve naive New Zealand albino rabbits, each weighing 2.5-3.0 $\mathrm{kg}$, served as the subjects. They were housed in individual cages, maintained on a fixed daily diet, and given water ad libitum. Treatment of animals and surgical procedures were in accordance with an approved animal welfare protocol.

Before training, animals were surgically prepared with a headstage that included a 26-gauge, stainless steel guide cannula implanted in the left anterior interpositus nucleus. Subjects were preanesthetized with $5 \mathrm{mg} / \mathrm{kg}$ acepromazine, and their skulls were immobilized in a stereotaxic restrainer. Anesthesia was maintained with isofluorene (1\%-2\% mixed in oxygen) throughout the operation. After exposing the skull, four holes were drilled to accommodate small screws for fixing the headstage, and a craniotomy was drilled lateral to lambda and covered with bone wax. After positioning the head with lambda $1.5 \mathrm{~mm}$ ventral to bregma, the tip of the guide cannula was placed at stereotaxic coordinates $0.7 \mathrm{~mm}$ anterior, $5.0 \mathrm{~mm}$ left lateral, and 13.3 $\mathrm{mm}$ ventral to lambda. A large screw (for attaching the infrared recording device) and the cannula were then secured with dental acrylic, and any areas exposing the skull were sutured. Finally, two stainless steel stimulating electrodes were implanted in periorbital areas rostral and caudal to the left eye. Subjects were allowed at least $1 \mathrm{wk}$ of recovery before experimentation.

\section{Drugs and Infusions}

We used a $200 \mu \mathrm{M}$ solution of the $\mathrm{GABA}_{\mathrm{A}}$ antagonist picrotoxin (Sigma Chemical Co., molecular weight $=602.6)$ dissolved in artificial cerebrospinal fluid (ACSF). The ACSF solution contained $119 \mathrm{mM} \mathrm{NaCl}, 2.5 \mathrm{mM} \mathrm{KCl}, 1.2 \mathrm{mM} \mathrm{NaH}_{2} \mathrm{PO}_{4}, 2 \mathrm{mM} \mathrm{MgCl}{ }_{2}, 2$ $\mathrm{mM} \mathrm{CaCl}, 26 \mathrm{mM} \mathrm{NaHCO}, 10 \mathrm{mM}$ D-glucose, and $20 \mathrm{mM}$ HEPES, and was adjusted to $\mathrm{pH}$ 7.35. Each solution was delivered to the anterior interpositus nucleus with an injector assembly consisting of a 50- $\mu \mathrm{L}$ Hamilton gastight syringe that was coupled, via polyethylene tubing, to a stainless steel internal cannula (33 gauge) that protruded $1.2 \mathrm{~mm}$ beyond the tip of the guide cannula. During test sessions, $1 \mu \mathrm{L}$ of solution was infused through the cannula at a rate of $0.5 \mu \mathrm{L} / \mathrm{min}$, using an electronic pump to drive the injector assembly. Then, 25 min later, a second infusion of $1 \mu \mathrm{L}$ was administered, and $3 \mathrm{~min}$ after terminating the infusion the test trials were initiated. The effective amount of picrotoxin infused during a drug test was 0.4 nmole.

\section{Apparatus}

As described previously, two custom-designed chambers were used in the experiments (Ohyama and Mauk 2001). Briefly, each was equipped with a speaker connected to an audio source module (Coulbourn Instruments) that generated tones and a pair of isolated pulse stimulators (A-M Systems model 2100) that delivered electrical pulses through the periorbital electrodes. An infrared emitter/detector attached to the headstage of each rabbit was used to record movements of the left external eyelid by detecting changes in the amount of reflected light.

The CS was a $1.0-$ or $9.5-\mathrm{kHz}$ pure tone $(85 \mathrm{~dB}, 70 \mathrm{~dB}$ background noise) or a light presented to the right eye (contralateral to the trained eye) through a light-emitting diode $(10 \mathrm{~mm}$ round, $250 \mathrm{mcd}, 585 \mathrm{~nm}$ peak emission wavelength; RadioShack, Cat. No. 276-216). The US was a current pulse $(100 \mathrm{~Hz}, 1 \mathrm{msec}$ pulse width, $0.8 \sim 2.5 \mathrm{~mA}$ ). Stimulus presentation was controlled by custom-designed software. Data were sampled at a rate of $1 \mathrm{kHz}$, and individual sweeps consisting of 2500 data points $(200 \mathrm{msec}$ before and $2300 \mathrm{msec}$ after CS onset) were collected for each trial and stored for subsequent offline analysis.

\section{Conditioning Procedure}

At the start of each daily training or test session, maximum eyelid closure in each animal was calibrated by either applying one to several electric pulses through the periorbital electrode or by a touch above the left eye to elicit a full eyelid closure. The voltageto-millimeter relationship was then determined assuming full eyelid closure to be $6 \mathrm{~mm}$.

Training sessions with CS1 or CS2 consisted of 12 nine-trial blocks, with each block containing eight paired CS-US trials and one CS-alone trial. The 550-msec CS coterminated with the 50msec US on paired trials, and occurred without the US on CSalone trials. For pre- and posttraining generalization tests (Fig. $2 \mathrm{~A}, \mathrm{~B}), \mathrm{ACSF}$ or picrotoxin was first infused, after which tones $(1.0,1.85,3.55,6.1$, and $9.5 \mathrm{kHz} ; 85 \mathrm{~dB})$ and light were presented repeatedly without the US. Each stimulus occurred once in a pseudorandom order within a six-trial block for nine blocks. We counterbalanced the order of the posttraining tests, but collapsed the data because there was no order effect.

The final picrotoxin test after training with CS2 (see Results, Alternative CS Control) consisted of 12 nine-trial blocks, each comprised of seven paired CS2-US trials with CS2 and CS1 occurring alone on the first and fifth trials, respectively. Picrotoxin was infused after the first three blocks, after which the remaining nine blocks were presented.

In all training and test sessions, the mean intertrial interval was $30 \pm 10 \mathrm{sec}$.

\section{Generalization Testing}

We designed the generalization tests to minimize the effects of repeated testing. To prevent stimulus pre-exposure effects and allow direct comparisons between the pre- and posttraining tests, we used a relatively small number of trials (i.e., 54) equated across tests (see Solomon and Moore 1975 for a lack of CS preexposure effect on posttraining generalization gradients). In the posttraining tests, we infused ACSF or picrotoxin and then tested for CRs or short-latency responses to test stimuli presented alone (Siegel et al. 1968; Liu 1971; Solomon and Moore 1975; Powell and Moore 1980). We opted for testing in extinction rather than interspersing occasional test trials among paired CS-US trials to (1) provide more test trials per session; (2) prevent sharpening of the generalization gradient with differential reinforcement (Liu 1971; Moore and Mis 1973; Powell and Moore 1980); and (3) take advantage of the strong resistance to extinction of short-latency responses (Perrett and Mauk 1995; Medina et al. 2001). We also chose this method in hopes of maintaining the relative shapes of the generalization gradients for CRs and short-latency responses, on the assumption that decremental processes related to extinction and/or the infusion itself (e.g., caused by picrotoxin leaking to the cerebellar cortex and abolishing CRs, inactivating only part of the cerebellar cortex and sparing its capacity for gradually extinguishing short-latency responses [Medina et al. 2000], etc.) 
would affect responses to each test stimulus equally (Siegel et al. 1968; Liu 1971; Solomon and Moore 1975; Powell and Moore 1980).

\section{Data Analysis}

Measures of eyelid closure such as latency to onset, latency to criterion (time from CS onset at which eyelid closure attained criterion), and magnitude were calculated for each trial using custom-designed software. A CR was defined as a closure of the eyelid of at least $0.3 \mathrm{~mm}$ occurring within $500 \mathrm{msec}$ of CS onset. Response magnitude on CS-alone trials was defined as the maximum attained within 1000 msec of CS onset because peak eyelid closure often occurred only after $500 \mathrm{msec}$. During generalization tests in picrotoxin, a short-latency response was defined as a $\mathrm{CR}$ with latency to criterion $<200 \mathrm{msec}$, and response magnitude on CS-alone trials as the maximum attained within $200 \mathrm{msec}$ after CS onset.

Statistical testing of differences in means was conducted by RM ANOVAs and $t$-tests, and differences in frequency distributions were assessed using a log-linear test (Bishop et al. 1975). In the final picrotoxin test, the treatment effect was assessed with a one-tailed independent-sample $t$-test comparing onset latencies for the last 16 preinfusion and first 16 postinfusion CRs to CS2. The effect on CRs to CS1 was assessed similarly, although with fewer pre- and postinfusion trials (five to nine trials each, with some preinfusion CRs taken from the end of the second retraining day with CS1).

\section{Criterion for Cannula Placement}

We considered cannula placement appropriate if at least six (out of a possible nine) CRs occurred to CS1 in the first posttraining picrotoxin test, and $>70 \%$ of these were short-latency responses. This rather stringent criterion was used because many lighttrained animals showed responses to CS1 that were smaller and less frequent than the short-latency responses for tone-trained animals (i.e., not reaching the criterion of $0.3 \mathrm{~mm}$ ), and we could not assess whether the few that did occur were caused by a genuine drug effect. Of 12,11 , and 35 animals trained, respectively, with the $1.0-\mathrm{kHz}$ tone, $9.5-\mathrm{kHz}$ tone, and the light as CS1, four animals each met this criterion. Histological examination (see Garcia and Mauk 1998 for details) confirmed that, in general, the cannula placements for subjects exhibiting short-latency responses were near or in the anterior interpositus nucleus, whereas those for subjects in which picrotoxin infusions had no effect were far from it. A major reason for the relative difficulty of obtaining robust short-latency responses in light-trained animals may have been that the contralateral monocular light provided a much weaker input to the cerebellum than binaural tones, a view supported by the slower acquisition for the light compared with either tone (see Results, Initial Acquisition of CRs).

\section{ACKNOWLEDGMENTS}

This work was supported by NIMH grants (MH46904 and MH57051) to M.D.M. We thank Nichole M. Taylor for performing histology and Matthew Murphy for helpful comments on the manuscript.

The publication costs of this article were defrayed in part by payment of page charges. This article must therefore be hereby marked "advertisement" in accordance with 18 USC section 1734 solely to indicate this fact.

\section{REFERENCES}

Aizenman, C.D. and Linden, D.J. 2000. Rapid synaptically driven increases in the intrinsic excitability of cerebellar deep nuclear neurons. Nat. Neurosci. 3: 109-111.

Alkon, D.L. 1984. Calcium-mediated reduction of ionic currents: A biophysical memory trace. Science 226: 1037-1045.

Askenov, D.P., Zenitsky, G.D., Irwin, K., Nilaweera, W.U., and Bracha, V. 2002. Stimulus specificity of neuronal responses in the interposed nuclei during the expression of conditioned eyeblinks. Soc. Neurosci. Abstr. 28: 79.5 .

Bao, S., Chen, L., Kim, J.J., and Thompson, R.F. 2002. Cerebellar cortical inhibition and classical eyeblink conditioning. Proc. Natl. Acad. Sci. 99: 1592-1597.

Bishop, Y.M.M., Fienberg, S.E., and Holland, P.W. 1975. Discrete multivariate analysis: Theory and practice. MIT Press, Cambridge, MA.

Bitterman, M.E. 1979. Generalization. In Animal learning: Survey and analysis (eds. M.E. Bitterman et al.), pp. 385-412. Plenum Press, New York.

Fiala, J.C., Grossberg, S., and Bullock, D. 1996. Metabotropic glutamate receptor activation in cerebellar Purkinje cells as substrate for adaptive timing of the classically conditioned eye-blink response. $J$. Neurosci. 16: 3760-3774.

Garcia, K.S. and Mauk, M.D. 1998. Pharmacological analysis of cerebellar contributions to the timing and expression of conditioned eyelid responses. Neuropharmacology 37: 471-480.

Garcia, K.S., Steele, P.M., and Mauk, M.D. 1999. Cerebellar cortex lesions prevent acquisition of conditioned eyelid responses. $J$. Neurosci. 19: 10940-10947.

Garcia, K.S., Mauk, M.D., Weidemann, G., and Kehoe, E.J. 2003. Covariation of alternative measures of responding in rabbit (Oryctolagus cuniculus) eyeblink conditioning during acquisition training and tone generalization. Behav. Neurosci. 117: 292-303.

Gluck, M.A., Reifsnider, E.S., and Thompson, R.F. 1990. Adaptive signal processing and the cerebellum: Models of classical conditioning and VOR adaptation. In Neuroscience and connectionist theory (eds. M. Gluck and D. Rumelhart), pp. 131-185. Lawrence Erlbaum Associates, Hilldale, NJ.

Grossi, S. and Pettorossi, V.E. 2001. Synaptic plasticity in the medial vestibular nuclei: Role of glutamate receptors and retrograde messengers in rat brainstem slices. Prog. Neurobiol. 64: 527-553.

Hansel, C., Linden, D.J., and D'Angelo, E. 2001. Beyond parallel fiber LTD: The diversity of synaptic and non-synaptic plasticity in the cerebellum. Nat. Neurosci. 4: 467-475.

Hartell, N.A. 2002. Parallel fiber plasticity. Cerebellum 1: 3-18.

Hesslow, G. and Ivarsson, M. 1994. Suppression of cerebellar Purkinje cells during conditioned responses in ferrets. Neuroreport 5: 649-652.

Holt, P.E. and Kehoe, E.J. 1985. Cross-modal transfer as a function of similarities between training tasks in classical conditioning of the rabbit. Anim. Learn. Behav. 13: 51-59.

Kehoe, E.J. 1988. A layered network model of associative learning: Learning-to-learn and configuration. Psychol. Rev. 95: 411-433.

Kehoe, E.J. and Holt, P.E. 1984. Transfer across CS-US intervals and sensory modalities in classical conditioning of the rabbit. Anim. Learn. Behav. 12: 122-128.

Kehoe, E.J. and Napier, R.M. 1991. Temporal specificity in cross-modal transfer of the rabbit nictitating membrane response. J. Exp. Psychol.: Anim. Behav. Proc. 17: 26-35.

Kehoe, E.J., Morrow, L.D., and Holt, P.E. 1984. General transfer across sensory modalities survives reductions in the original conditioned reflex in the rabbit. Anim. Learn. Behav. 12: 129-136.

Kehoe, E.J., Horne, A.J., and Macrae, M. 1995. Learning to learn: Real-time features and a connectionist model. Adapt. Behav. 3: 235-271.

Kistler, W.M. and De Zeeuw, C.I. 2002. Dynamical working memory and timed responses: The role of reverberating loops in the olivo-cerebellar system. Neural Comput. 14: 2597-2626.

Kleim, J.A., Freeman Jr., J.H., Bruneau, R., Nolan, B.C., Cooper, N.R., Zook, A., and Walters, D. 2002. Synapse formation is associated with memory storage in the cerebellum. Proc. Natl. Acad. Sci. 99: 13228-13231.

Liu, S.S. 1971. Differential conditioning and stimulus generalization of the rabbit's nictitating membrane response. J. Comp. Physiol. Psychol. 77: 136-142.

Macrae, M. and Kehoe, E.J. 1999. Savings after extinction in conditioning the rabbit's nictitating membrane response. Psychobiology 27: 85-94.

Mauk, M.D. and Donegan, N.H. 1997. A model of Pavlovian eyelid conditioning based on the synaptic organization of the cerebellum. Learn. Mem. 3: 130-158.

McCormick, D.A. and Thompson, R.F. 1984. Cerebellum: Essential involvement in the classically conditioned eyelid response. Science 223: 296-299.

Medina, J.F. and Mauk, M.D. 1999. Simulations of cerebellar motor learning: Computational analysis of plasticity at the mossy fiber to deep nucleus synapse. J. Neurosci. 19: 7140-7151.

. 2000. Computer simulation of cerebellar information processing. Nat. Neurosci. 3 Suppl.: 1205-1211.

Medina, J.F., Garcia, K.S., Nores, W.L., Taylor, N.M., and Mauk, M.D. 2000. Timing mechanisms in the cerebellum: Testing predictions of a large-scale computer simulation. J. Neurosci. 20: 5516-5525.

Medina, J.F., Garcia, K.S., and Mauk, M.D. 2001. A mechanism for savings in the cerebellum. J. Neurosci. 21:4081-4089.

Miles, F.A. and Lisberger, S.G. 1981. Plasticity in the vestibulo-ocular 
Ohyama et al.

reflex: A new hypothesis. Annu. Rev. Neurosci. 4: 273-299.

Moore, J.W. and Mis, F.W. 1973. Differential conditioning along two dimensions and stimulus generalization of the rabbit's nictitating membrane response. Bull. Psychon. Soc. 1: 123-125.

Moore, J.W., Desmond, J.E., and Berthier, N.E. 1989. Adaptively timed conditioned responses and the cerebellum: A neural network approach. Biol. Cybern. 62: 17-28.

Napier, R.M., Macrae, M., and Kehoe, E.J. 1992. Rapid reacquisition in conditioning of the rabbit's nictitating membrane response. J. Exp. Psychol.: Anim. Behav. Proc. 18: 182-192.

Ohyama, T. and Mauk, M.D. 2001. Latent acquisition of timed responses in cerebellar cortex. J. Neurosci. 21: 682-690.

Perrett, S.P. and Mauk, M.D. 1995. Extinction of conditioned eyelid responses requires the anterior lobe of cerebellar cortex. J. Neurosci. 15: 2074-2080.

Perrett, S.P., Ruiz, B.P. and Mauk, M.D. 1993. Cerebellar cortex lesions disrupt the learning-dependent timing of conditioned eyelid responses. J. Neurosci. 13: 1708-1718.

Peterson, B.W., Kinney, G.A., Quinn, K.J., and Slater, N.T. 1996. Potential mechanisms of plastic adaptive changes in the vestibulo-ocular reflex. Ann. N.Y. Acad. Sci. 956: 499-512.

Powell, G.M. and Moore, J.W. 1980. Conditioning of the nictitating membrane response in rabbit (Oryctolagus cuniculus) with electrical brain-stimulation as the unconditioned stimulus. Physiol. Behav. 25: 205-216.

Racine, R.J., Wilson, D.A., Gingell, R., and Sunderland, D. 1986. Long-term potentiation in the interpositus and vestibular nuclei in the rat. Exp. Brain Res. 63: 158-162.

Raymond, J.L., Lisberger, S.G., and Mauk, M.D. 1996. The cerebellum: A neuronal learning machine? Science 272: 1126-1131.

Robinson, D.A. 1976. Adaptive gain control of vestibuloocular reflex by the cerebellum. J. Neurophysiol. 39: 954-969.
Schreurs, B.G. and Kehoe, E.J. 1987. Cross-modal transfer as a function of initial training level in classical conditioning with the rabbit. Anim. Learn. Behav. 15: 47-54.

Schreurs, B.G., Tomsic, T., Gusev, A., and Alkon, D.L. 1997. Dendritic microzones and occluded long-term depression after classical conditioning of the rabbit's nictitating membrane response. J. Neurophysiol. 77: 86-92.

Schreurs, B.G., Gusev, P.A., Tomsic, D., Alkon, D.L., and Shi, T. 1998. Intracellular correlates of acquisition and long-term memory of classical conditioning in Purkinje cell dendrites in slices of rabbit cerebellar lobule HVI. J. Neurosci. 18: 5498-5507.

Siegel, S., Hearst, E., and George, N. 1968. Generalization gradients obtained from individual subjects following classical conditioning. $J$. Exp. Psychol. 78: 171-174.

Smith, M.R., Nelson, A.B., and Du Lac, S. 2002. Regulation of firing response gain by calcium-dependent mechanisms in vestibular nucleus neurons. J. Neurophysiol. 87: 2031-2042.

Solomon, P.R. and Moore, J.W. 1975. Latent inhibition and stimulus generalization of the classically conditioned nictitating membrane response in rabbits (Oryctolagus cuniculus) following hippocampal ablation. J. Comp. Physiol. Psychol. 89: 1192-1203.

Steinmetz, J.E. 2000. Brain substrates of classical eyeblink conditioning: A highly localized but also distributed system. Behav. Brain Res. 110: $13-24$.

Tracy, J.A., Britton, G.B., and Steinmetz, J.E. 2001. Comparison of single unit responses to tone, light, and compound conditioned stimuli during rabbit classical eyeblink conditioning. Neurobiol. Learn. Mem. 76: $253-267$.

Received July 14, 2003; accepted in revised form August 11, 2003. 


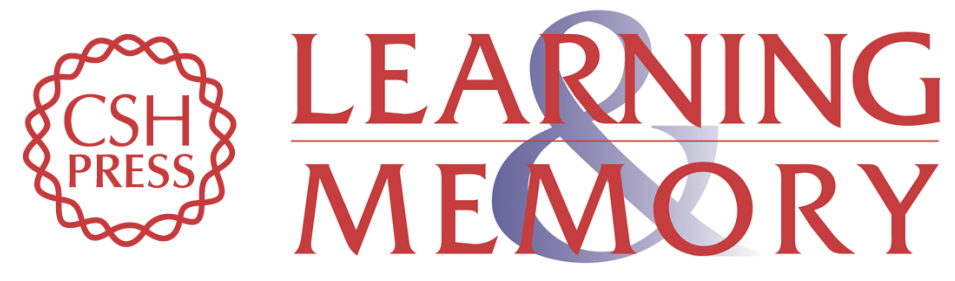

\section{Stimulus Generalization of Conditioned Eyelid Responses Produced Without Cerebellar Cortex: Implications for Plasticity in the Cerebellar Nuclei}

Tatsuya Ohyama, William L. Nores and Michael D. Mauk

Learn. Mem. 2003, 10:

Access the most recent version at doi:10.1101//m.67103

References This article cites 39 articles, 14 of which can be accessed free at: http://learnmem.cshlp.org/content/10/5/346.full.html\#ref-list-1

License

Email Alerting

Receive free email alerts when new articles cite this article - sign up in the box at the Service top right corner of the article or click here. 